\section{BDA BULLETIN}

- As a result of a partnership between the BDA in Northern Ireland, sponsors First Trust Bank and the dental faculty at Queen's University, Belfast, a prize fund worth $£ 500$ is being offered to dental students studying special care dentistry in their penultimate year at Queen's University, Belfast. Fourth year students are encouraged to compete for the prize by submitting a poster presentation considering how challenges presented in the care of a patient with special needs may be managed effectively.

- The BDA is this year marking the first 200 dental practices achieving Gold Membership of its Good Practice Scheme. Practices attain Gold Membership by maintaining Good Practice Scheme member status for ten consecutive years. Practices were invited to attend an exclusive celebration at April's British Dental Conference and Exhibition.

- The auction organised by the BDA and held at the 2013 British Dental Conference and Exhibition raised nearly $£ 9,000$ for the BDA
Benevolent Fund and Bridge2Aid. Attendees successfully bid for a wide range of lots including luxury experiences, sporting memorabilia and dental equipment and training packages.

- A BDA-organised petition articulating opposition to proposals to restrict the availability of Health Service dental treatment in Northern Ireland has attracted more than 8,700 patient signatures.

- The BDA has warned that a Government commitment to improve the oral health of the youngest children could be jeopardised if the shortfall in the dental public health workforce is not addressed. Despite previous assurances that the many gaps in the Consultant in Dental Public Health (CDPH) workforce will be addressed, recruitment for a number of posts has yet to take place and it is not clear that the funding for it to commence is available.

- April's British Dental Conference and Exhibition attracted more than 5,400 dental professionals, a record number of attendees and a nine percent increase on 2012.

\section{HONOURS, AWARDS, APPOINTMENTS}

Implantology scholarship

Dr Aws Alani, an SpR at Newcastle Dental Hospital, has won a $\$ 40,000$ scholarship with the International Team for Implantology to observe and treat patients at The Holland Bloorview Kids Rehabilitation Hospital in Toronto, Canada.

\section{Tenth birthday}

The British Lingual Orthodontic Society (BLOS) has celebrated its tenth birthday with a lingual training day. More than 25 orthodontic nurses and therapists gathered for the training day, which was delivered by three BLOS committee members. BLOS was founded by eight orthodontists and today has over 150 members.

\section{Lifetime achievement}

Glasgow-based dental laboratory owner Alex Littlejohn from Dental Technology Services International was presented with this year's Scottish Dental Lifetime Achievement Award at the Scottish Dental Awards. Mr Littlejohn was the first person to introduce dental veneers to the UK in the 1980s and has spent more than five decades in the profession.

\section{Dentist of the year}

David MacPherson from Whitemoss Dental Practice in East Kilbride won Dentist of the Year at the Scottish Dental Awards. Most Valuable Contribution to Patient Care was awarded to Hari Lal from Livingston and Most Attractive Practice went to Your Perfect Smile Dental Clinic in Aviemore.

\section{DENTIST REQUIRED FOR DICTIONARY}

Market House Books Ltd is looking for a dentist to contribute to the revision of the Oxford Concise Medical Dictionary (8th edition, 2010), by reviewing about 234 dental entries and adding as many new entries as are required to bring the dictionary up to date.

The Oxford Concise Medical Dictionary contains over 12,000 entries covering all aspects of medicine. It is illustrated with clear line drawings and contains useful appendices. First published in 1980, the dictionary is written by a team of experts, mostly of consultant status, and revised about every four years. For many years the dentistry entries were revised by Tom Pitt Ford, Professor of Endodontology and Director of Education at King's College London Dental Institute, who died in 2008.

A key feature of the dictionary is its avoidance of medical jargon, making it clear and accessible for students, healthcare professionals and trainees and paramedical workers.

Contributors will be paid and credited in the 9th edition of the dictionary and the revision must be completed by spring 2014. Please contact Elizabeth Martin at martin@mhbref.com.

\title{
SPRAY GREATLY IMPROVES XEROSTOMIA
}

Researchers from the universities of Granada and Murcia have confirmed the effectiveness of a spray containing $1 \%$ malic acid, which greatly improves xerostomia caused by anti-depressant drugs. ${ }^{1}$ The malic acid combined with xylitol and fluoride in a spray format stimulates saliva production.

As the main author of the study, University of Granada lecturer Gerardo Gómez Moreno explained that one of the main causes of xerostomia is the consumption of different medications. 'There are over 500 drugs, belonging to 42 pharmacological groups, which can provoke xerostomy as a side effect. Those that are most related are antidepressants, the prescription of which has increased over recent years, thus leading to a higher number of patients with xerostomy ... above all in 45-50-year-olds.'

1. Gómez-Moreno G, Aguilar-Salvatierra A Guardia J et al. The efficacy of a topical sialogogue spray containing 1\% malic acid in patients with antidepressant-induced dry mouth: a double-blind randomized clinical trial. Depress Anxiety 2013; 30: $137-142$.

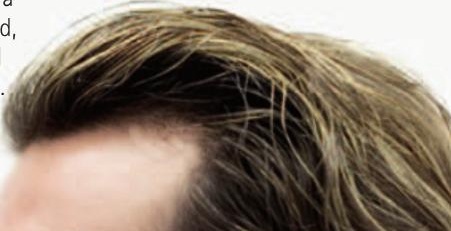

